\title{
Comparison of Outcome of Teenage Pregnancy with Non- teenage pregnancy
}

\author{
Deepanjali Sharma, Sailaja Ghimire, MeenaJha, Gehanath Baral \\ Paropakar Maternity and Women's Hospital, Thapathali, Kathmandu, Nepal \\ Received: December 27, 2019 \\ Accepted: March 15, 2020
}

\section{ABSTRACT}

\begin{abstract}
Aims: To analyze the maternal and fetal outcome in teenage pregnancy ( $\leq 19$ years) with that of pregnancy at optimal childbearing age group (20- 34 years).
\end{abstract}

Methodology: This was a hospital based observational analytical study conducted at Paropakar Maternity and Women's Hospital in Kathmandu from August 2016 to February 2017.Results were analyzed using SPSS 21 taking p-value $\leq 0.05$ as statistically significant.

Results: There were 200 cases in each group ( $\leq 19$ and 20-34 years). Anemia $(p=0.001)$, hypertensive disorder of pregnancy ( $p=0.001)$, preterm delivery $(\mathrm{p}=0.001)$, Cesarean Section rate $(\mathrm{p}=0.006), 5$-minute Apgar score $(\mathrm{p}=0.035)$, low birth weight $(\mathrm{p}=0.017)$ and neonatal admission rates $(\mathrm{p}=0.018)$ were significantly high in teenage pregnancy.

Conclusions: Both maternal and neonatal complications are increased in teenage pregnancy in comparison to the optimal reproductive age group.

Key words: complications, pregnancy, teenage

Citation : Sharma D, Ghimire S, Jha M, Baral G. Comparison of Outcome of Teenage Pregnancy with Non- teenage pregnancy. Nep J Obstet Gynecol. 2020;15(30):28-30. DOI: 10.3126/njog.v15i1.29336

\section{INTRODUCTION}

The term 'Teenage pregnancy' refers to the individual between 13-19 years becoming pregnant. Teenage pregnancy is an important social and public health problem all over the world. ${ }^{1}$ Adolescence is a period of transition from childhood to adulthood. These are the formative years where maximum amount of physical, psychological and behavioral changes takes place in person's life. ${ }^{2}$ Teenage pregnancy is a public health concern both in developed and developing world. ${ }^{3,4}$ It is estimated that globally about 13 million infant born to adolescents and of which more than $90 \%$ occur in developing countries, especially in sub- Saharan Africa. ${ }^{5}$ Worldwide rates of teenage pregnancy range from 2.9 per 1000 in South Korea to 143 per 1000 in some sub-Saharan African countries. ${ }^{6}$ South Asian countries (India, Pakistan, Sri Lanka, Nepal, Maldives, Bhutan and Bangladesh) have high proportions of teenage pregnancies, since early marriage is common and there is a social expectation to have a child soon after marriage. ${ }^{7,8}$ Teenage pregnancy is associated with grave consequences for the mother, fetus/ neonate and the community. ${ }^{9}$ Adverse maternal outcomes of teenage pregnancy includes preterm labour, anaemia, hypertensive disorders of pregnancy, obstetric fistulas, mental illness and high rate of caesarean sections for cephalo-pelvic disproportion and fetal distress. Adverse fetal outcomes include preterm births, low birth weight infants, still births, birth asphyxia, respiratory distress syndrome and birth trauma or injury.Teenage delivery rate is $13 \%$ at study site. Thus this study would be helpful to assess the age related pregnancy outcome especially in teenage pregnancy at the study site.

\section{METHODS}

This is comparative study of teenage pregnancy of 19 years or less with at least 22 weeks of singleton pregnancy and control group was from 20-34 years of age irrespective of parity. Written informed consent

\section{CORRESPONDENCE}

Dr Deepanjali Sharma

Paropakar Maternity and Women's Hospital, Thapathali, Kathmandu, Nepal

Email: dipa22.ds@gmail.com; Mobile: +977-9845114857 
was taken after institutional approval. Study variables were obstetric complications, mode of delivery, Apgar score, weight and NICU stay.Case management was according to the hospital protocol. Data entry analysis was done using SPSS 22 spreadsheet.

\section{RESULTS}

Total number of deliveries within the study period at this hospital was 9464, among them 1230 were teenage deliveries (13\%). There were 200 cases enrolled in each study arm- teenage pregnancy group ( $\leq 19$ years) and control group (20-34 years); 198 $(99 \%)$ were at age 16-19 years whereas 183 (91\%) were at 20-29 years of control group [Figure-1].

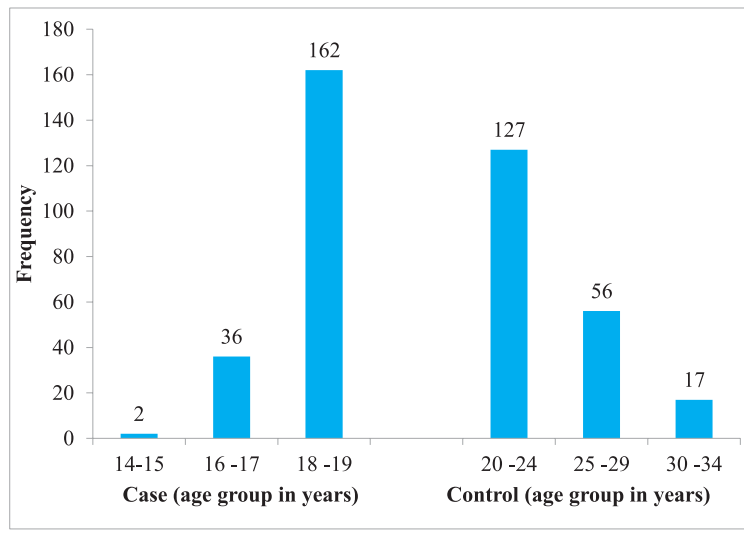

Figure-1: Age group distribution

Anemia, hypertensive disorder of pregnancy (HDP), preterm delivery and Cesarean Section (CS) rate were significantly higher in teenage pregnancy. PPH was also higher in teenage group but was not statistically significant. GDM, APH and PROM were not statistically significant [Table-1].

Table-1: Complications during pregnancy

\begin{tabular}{|l|c|c|c|}
\hline Variables & Case (\%) & Control (\%) & p-value \\
\hline Anemia & $13(6.5)$ & $1(0.5)$ & 0.001 \\
\hline HDP & $62(31)$ & $34(17)$ & 0.001 \\
\hline Preterm & $31(15.5)$ & $11(5.5)$ & 0.001 \\
\hline CS & $69(34.5)$ & $38(19)$ & 0.006 \\
\hline PPH & $8(4)$ & $1(0.5)$ & 0.126 \\
\hline GDM & $0(0)$ & $2(1)$ & 0.156 \\
\hline APH & $3(1.5)$ & $1(0.5)$ & 0.321 \\
\hline PROM & $7(3.5)$ & $10(5)$ & 0.457 \\
\hline
\end{tabular}

Likewise Apgar score of 3 or less at 5 minutes (5\% vs $1 \%, \mathrm{p}=0.035)$ [Table-2], low birth weight ( $18 \%$ vs $9.5 \%, p=0.017$ ) [Figure-2] and NICU admission rate
( $15 \%$ vs $7.5 \%, p=0.018)$ were significantly higher in teenage group.

\begin{tabular}{|c|c|c|c|}
\hline Apgar score at 5 minute & Case & Control & p-value \\
\hline 0 & 4 & 0 & \multirow[t]{4}{*}{0.035} \\
\hline $1-3$ & 6 & 2 & \\
\hline $4-6$ & 16 & 9 & \\
\hline $7-10$ & 174 & 189 & \\
\hline
\end{tabular}

Table-2: Apgar score at 5-minute

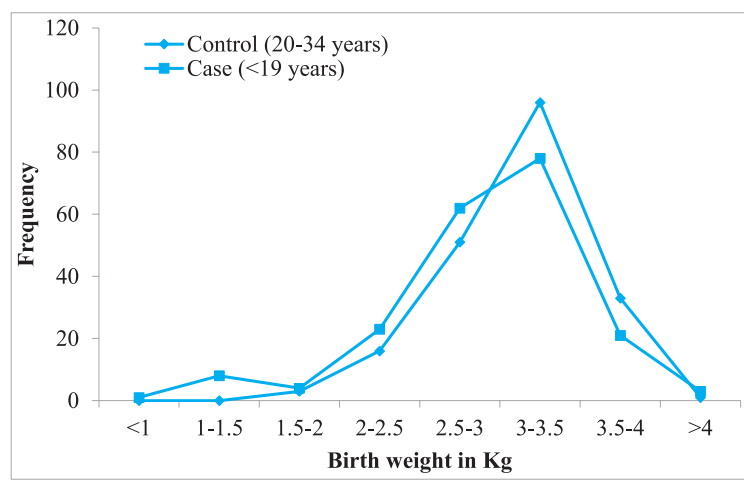

Figure-2: Birth weight distribution in $\mathrm{Kg}$

\section{DISCUSSION}

Teenage pregnancy is associated with grave consequences for the mother, fetus/neonate and the community. ${ }^{9}$ Despite accounting for only $11 \%$ births worldwide, adolescent women carry $23 \%$ of overall burden of disease (in terms of disability adjusted life years) due to pregnancy and childbirth among women of all ages. ${ }^{10}$ Total number of deliveries within the study period at our hospital was 9464, among which 1230 were teenage deliveries that comprised of $13 \%$ of total deliveries. A study done by Lama et $\mathrm{al}^{11}$ in 2005-2009 in Nepal found that the prevalence of teenage pregnancy was $11.1 \%$ of total 3144 deliveries studied which is similar to my study that is $13 \%$.

Eighty-one percent (81\%) of the teenage pregnancies belonged to 18-19 years. The maximum age in the control group was seen in 20-24 years (63.5\%). Study done by Mukhopadhyay $\mathrm{P}$ et $\mathrm{al}^{9}$ found that maximum number of teenage mothers $(n=312 ; 89 \%)$ belonged to $18-19$ years' age which was similar to my study $(\mathrm{n}=162 ; 81 \%)$.

Anemia, hypertensive disorder of pregnancy, preterm deliveriesand Cesarean Section rate were significantly common complications in teenage group that is comparable with the studies done by 
Ayuba II et al. ${ }^{12}$ In contrast to it, Hoque M. et $\mathrm{al}^{13}$ found significantly higher rate of caesarean delivery in adult mothers. Postpartum hemorrhage was higher but not significant in contrast to the report of Ayuba II et al. ${ }^{12}$

Similarly significantly higher low birth weight rate and 5-minute Apgar less than 4 like this study was also reported by Egbe TO et al. ${ }^{14}$ NICU admission was significant $(p=0.018)$ in contrast to the study done by Al-Haddabi R et $\mathrm{al}^{15}(\mathrm{p}=0.18)$.

\section{CONCLUSIONS}

Teenage pregnancy was associated with anemia, hypertensive disorder and preterm delivery; and low birth weight babies along with APGAR score $<4$ at 5 min. Non-teenage mothers were more likely to have vaginal delivery. No significant difference was found in postpartum maternal morbidity and mortality.

\section{REFERENCES}

1. The WHO study group on young people and health for all by the year 2000. Young people's health-a challenge for society. Geneva: World health organization, WHO technical report series. $1986 ; 731: 1-37$.

2. Department of reproductive health and research. WHO library cataloguing in publication data, WHO, Geneva; 2004.p.1-67.

3. Lawlor DA, Shaw M. Teenage pregnancy rates: high compared with where and when? J Royal Soc Med. 2004;97:1213

4. Myors K, Johnson M, Langdon R. Coping styles of pregnant adolescents. Public Health Nursing. 2001;18:24-32.

5. McIntosh N, Helms P, Smith R, editors. Forfar and Arneil's text book of Paediatrics, 6th edition. Edinburg, Churchill Livingstone, 2003; 449-56.

6. Mayor S. Pregnancy and childbirth are leading causes of death in teenage girls in developing countries. BMJ. 2004;328:1152-9.

7. Stone N, Ingham R, Simkhada P. Knowledge of sexual health issues among unmarried young people in Nepal. Asia-Pacific Popul J. 2003;18:33-54

8. Mathur S, Mehta M, Malhotra A. Youth reproductive health in Nepal: is participation the answer?. Engender Health, New York; 2004.p.73-5
9. Mukhopadhyay P, Chaudhuri RN, Paul B. Hospital-based Perinatal Outcomes and Complications in Teenage Pregnancy in India. J Health Popul Nutr. 2010;28:494-500.

10. MangiaterraV, Pendse R, McClure K, Rosen J. Department of making pregnancy safer (MPS). WHO MPS note; Adolescent pregnancy; 2008.p.108-14

11. Lama L, Shrestha S, Sharma A, Upadhyay S, Pathak MR. Immediate neonatal outcome of adolescent pregnant mother at Nepal Medical College Teaching Hospital. Nepal Med Coll J. 2013;15(2):117-21.

12. Ayuba II, Gani O. Outcoome of teenage pregnancy in the $\mathrm{Ni}$ ger Delta of Nigeria. Ethiop J Health Sci. 2012;22(1):45-50.

13. Hoque M, Hoque S. A comparison of obstetrics and perinatal outcomes of teenagers and older women: Experiences from rural South Africa. Afr J Prm Health Care Fam Med. 2010;2(1)171-6.

14. Egbe TO, Omeichu A, Halle-Ekae GE, Tchente CN, Egbe EN Oury JF. Prevalence and outcome of teenage hospital births at the buea health district, South West Region. Cameroon. Reprod Health. 2015;12:118.

15. Al-Haddabi R, Al-Bash M, Al-Mabaihsi N, Al-Maqbali N, AlDhughaishi T, Abu-Heija A. Obstetric and Perinatal Outcomes of Teenage Pregnant Women Attending a Tertiary Teaching Hospital in Oman. Oman Med J. 2014;29(6):399-403. 